Mots. Les langages du politique

Émotion dans les médias

Joseph Messinger, Ces gestes qui manipulent, ces mots qui influencent

\title{
Maurice Tournier
}

\section{(2) OpenEdition \\ Journals}

Édition électronique

URL : https://journals.openedition.org/mots/3593

DOI : $10.4000 /$ mots.3593

ISSN : 1960-6001

Éditeur

ENS Éditions

Édition imprimée

Date de publication : 1 juillet 2004

Pagination : 138

ISBN : 2-84788-057-7

ISSN : 0243-6450

\section{Référence électronique}

Maurice Tournier, "Joseph Messinger, Ces gestes qui manipulent, ces mots qui influencent », Mots. Les langages du politique [En ligne], 75 | 2004, mis en ligne le 23 avril 2008, consulté le 23 avril 2022. URL: http://journals.openedition.org/mots/3593 ; DOI : https://doi.org/10.4000/mots.3593 
Joseph Messinger,

Ces gestes qui manipulent, ces mots qui influencent,

2003, Paris, Éditions générales First, 414 pages.

Ce paragraphe ne vise pas à présenter le grand ouvrage d'un «spécialiste de la symbolique gestuelle», ainsi qu'il se dénomme, mais à faire connaitre, à travers lui, un type d' ' analyse» de la gestuelle qui se situe à l'opposé des recherches si rigoureuses et scrupuleuses de Geneviève Calbris. Dans ce livre, en effet, tout est interprétation.

Après une première partie qui définit ce qu'est la «manipulation » et dont l'aspect pamphlétaire n'est pas le plus inintéressant, viennent les «gestes manipulateurs» puis les «mots qui influencent». Une suite de portraits, plaisants ou ridicules, défilent de page en page, sans aucune analyse, aucune précaution, tirant, avec certitude, conclusions sur conclusions de l'intuition personnelle ou, au mieux, d'une certaine expérience de psychologue d'entreprise. C'est ainsi qu'à propos de «croisements", à partir de l'indubitable intuition que «tout croisement corporel est un code de protection du territoire mental», on apprend que «si votre interlocuteur est un homme droitier défensif (croisement du bras gauche dominant le droit) et que sa jambe gauche couvre la droite, il exprime l'échec de sa manœuvre», mais «s'il s'agit d'un homme droitier offensif (croisement du bras droit dominant le gauche) et que la jambe droite couvre la gauche, l'attitude est clairement calculatrice», que «doigts croisés, index pointés en avant et collés l'un à l'autre [est un] geste inattendu indiquant un donneur de leçon capable de couper les cheveux en quatre» et encore que «le croisement des doigts en chevron est un signal de trac pur et dur». Chapitre index, vous apprendrez que «tout contact entre les lèvres et l'un des index provoque une coupure de l'intelligence logique et de la réflexion qui l'accompagne» et vous aurez droit à: «l'index amoureux», «l'index barbichette», «l'index bluffeur», «l'index faux témoin», «l'index fleuret» etc. Psychologie intuitive des attitudes et non pas étude des «gestes qui manipulent», cet ouvrage non scientifique est, au bout du compte, simplement marrant. L'analyste en gestuelle peut se dispenser de le lire.

\section{Maurice Tournier}

Gilbert Rist (dir.),

Les mots du pouvoir, sens et non-sens de la rhétorique internationale, 2002, Nouveaux Cahiers de l'IUED, 208 pages.

Dans ce numéro des Nouveaux Cahiers de l'IUED, les auteurs, venus de divers horizons disciplinaires (sociologie politique, relations internationales, 